\title{
A INSERÇÃO DA PESQUISA CIENTÍFICA COMO INSTRUMENTO DE ENSINO NA EDUCAÇÃO PROFISSIONALIZANTE
}

\section{INSERTION OF SCIENTIFIC RESEARCH AS TEACHING TOOL FOR TEACHING IN VOCATIONAL EDUCATION}

\author{
Maiza Gabrielle Ribeiro Pereira *, Carla Lidiane **, Elson Barbosa da Silva Júnior, Lia Maria \\ Teixeira de Oliveira *
}

Universidade Federal Rural do Rio de Janeiro (*)

E-mail:maiza_mg@yahoo.com.br, elsonlica@yahoo.com.br, liamteixeira@bol.com.br

UNIGRENDAL $(* *)$

E-mail: carlalidiane@yahoo.com

\begin{abstract}
Resumo
O objetivo do trabalho foi comparar o conhecimento dos alunos antes e depois de atuarem em uma pesquisa científica. Abordando questões referentes ao ensino profissionalizante e as novas tecnologias da educação e ensino, trazendo procedimentos da pesquisa científica como ferramenta didática. O trabalho foi realizado no Centro Integrado de Educação Rural Vila Pavão (ES) com pesquisa qualitativa em educação com procedimentos do método analítico descritivo. Os resultados mostraram que a maioria dos alunos tinha dúvidas em todos os conteúdos no texto exploratório, mas após a execução do experimento as dúvidas diminuíram no entendimento geral, porém aumentaram questionamentos sobre o conteúdo específico, mostrando a ampliação dos horizontes conceituais, relevantes na formação profissionalizante.
\end{abstract}

Palavras-chave: tecnologia. ensino-aprendizagem. metodologia. professores. alunos.

\begin{abstract}
The objective of this study was to compare students' knowledge before and after acting in the scientific research. Addressing issues related to vocational education and new teaching technologies, bringing scientific research as a tool didacticism. The work was carried out, Vila Pavão-ES Center for Integrated Rural Education with qualitative research in education with procedures descriptive analytical method. The results showed that most students had doubts in all content in the exploratory text, but after running the experiment the doubts decreased in the overall understanding, but in the specific content increased, showing the expansion of the conceptual, relevant horizons in the formation vocational.
\end{abstract}

Keywords: technology. teaching-learning. methodology. teachers. students. 


\section{INTRODUÇÃO}

Os ensinos técnico e profissionalizante agrícola surgiram a partir de diversas estratégias políticosociais e econômicas para a aceleração do desenvolvimento urbano e rural do Brasil, tendo inicio no Governo Vargas após $1930^{1}$, quando se buscava implantar políticas intervencionistas visando a intensificação da industrialização brasileira. Esta visão política de planificação, em prol do acionamento de mecanismos institucionais para o avanço industrialista, levou à consolidação de uma legislação específica, definindo o ensino industrial como um dos ramos do sistema educacional, a partir do Decreto-Lei n. 4.073, de 30/01/1942, conhecido como Lei Orgânica do Ensino Industrial, durante a gestão do então ministro da Educação e Saúde Gustavo Capanema (MACHADO, 2012).

Dentro das políticas governamentais os processos de industrialização dos setores de produção no meio urbano, houve extensão de estratégias bastante produtivistas para o meio rural, inclusive aliada à necessidade de fixação do homem à terra, de forma que este pudesse ser inserido às mudanças necessárias à tecnificação e profissionalização do homem do campo. Por isso, em 1946, foi aprovada a Lei Orgânica do Ensino Agrícola, onde se previu a formação de técnicos agrícolas, cursos avulsos a serem ofertados pelas Secretarias de Agricultura, Ministério de Agricultura, Cursos de técnicos para formação do Administrador Rural, Diretores de escolas Agrícolas e de Economistas Domésticas.

Desta forma diversas escolas foram criadas pelo país e também adequadas, já que desde 1910 e 1918 existiam os Patronatos e Aprendizados Agrícolas, que se voltavam para uma visão pedagógica e de profissionalização de parcelas carentes e miseráveis da sociedade urbana e rural. Não que nesta instituição agrícola se visse apenas "o asilo" de jovens e crianças. Havia, sim, em torno destas instituições, um compromisso pautado nas mudanças sociais e econômicas do campo, embora carregada de preconceito com as classes carentes. Pensava-se, nestas instituições, profissionalizar os pobres para serem "cidadãos úteis" à sociedade que precisava de mudanças nos setores de produção da agropecuária. Para essas parcelas restava apenas a escola profissionalizante, que pedagogicamente compreendia que esses indivíduos necessitavam ser "civilizados", mais do que educados e escolarizados para a inclusão social e a inclusão no mundo do trabalho de forma mais

\footnotetext{
${ }^{1}$ Para maiores discussões ver MENDONÇA (2006).
} 
qualificada. Mendonça (2006) faz uma crítica aos processos de profissionalização no ensino agrícola voltados apenas para as parcelas mais carentes, quando naquele momento histórico a Eugenia fundamentava as propostas educacionais aos "desvalidos da sorte".

Naquele contexto socioeducacional e de trabalho as instituições de ensino agrícola foram sendo modificadas e também criadas para contemplarem principalmente a formação de técnicos agrícolas, que seriam formados com a missão de aumentar a produção nos campos brasileiros, cuja escola de educação profissional estava sustentada na racionalidade produtivista qualificando as parcelas que seriam a "mão de obra" para os processos de industrialização e de tecnificação da agricultura, de onde se apreende que essas mesmas parcelas seriam desapropriadas de seus conhecimentos práticos e de suas terras. Para esses a Escola preconizada nas dualidades de ensino-produção estava reservada (SAVIANI, 1994; GRAMSCI, 2001).

Atualmente os cursos técnicos em Agropecuária continuam existindo nas diversas instituições de ensino, porém não com os mesmos propósitos de atuação em seu campo profissional devido à ascensão dos cursos superiores e a mudança de visão na sua formação técnica para o trabalho, o que Antunes (2000) define como reestruturação produtiva do capital. O ensino profissionalizante esta cada vez mais criando características próprias às demandas atuais. De acordo com Manfredi (2002), a Educação Profissional é um processo condicionado e determinado de qualificação social, o que não levará diretamente ao trabalho ou emprego. Assim trata-se do ensino/aprendizagem de forma empírica, garantindo que a construção do saber científico se faça a partir da observação e aproximação com o fato existente, abandonando a visão produtivista de mercado que, como demonstrado, foi estabelecida no inicio da implementação do curso técnico agrícola no Brasil (MANFREDI, 2002).

Esta mudança requer novas metodologias pedagógicas de ensino, que levem o educando a compreensão real do conhecimento e a capacidade de inferir sobre um determinado assunto, alcançando a autonomia de sua própria aprendizagem (FREIRE, 1996; ZABALA, 1998). 
Para a educação de qualquer cidadão no mundo contemporâneo, é fundamental que ele tanto possua noção, no que concerne à ciência e tecnologia (CT), de seus principais resultados, de seus métodos e usos, quanto de seus riscos e limitações e também dos interesses e determinações (econômicas, políticas, militares, culturais etc.) que presidem seus processos e aplicações (MOREIRA, 2006).

A necessidade de novas metodologias no ensino agrícola perpassa pela própria evolução da agricultura no Brasil. Hoje a agricultura é a base do PIB nacional, isto se deve muito ao aumento de produtividade com a inovação tecnológica. Esta, por sua vez, é consequência da produção científica brasileira, que se concentra em grande parte nas áreas de pesquisas agrícolas e ciências naturais, levando o Brasil a ocupar o 13 lugar no ranking dos países com maior volume de produção científica do mundo. Entre 2002 e 2007, o número de publicações científicas saltou $110 \%$, com uma taxa de crescimento na elaboração de trabalhos científicos de $8 \%$ ao ano, enquanto a média mundial está em 2\%. De acordo com Murta (2004), a compreensão desta realidade é uma proposta de educação para a formação do pensamento complexo capaz de lidar com a complexidade do mundo, que vai ao encontro da visão de Gramsci (2001), onde o trabalho deve ser inserido na escola a partir de dois elementos educativos fundamentais: noções de ciências naturais e noções de direitos e deveres do cidadão.

Porém a produção científica, vista sob a perspectiva epistemológica, não esta sendo suficientemente valorizada como suporte educacional nas escolas profissionalizantes agrícolas pelo país, levando a uma pergunta simples: quantos artigos científicos um aluno de um curso técnico ou não leu antes de entrar na faculdade? Provavelmente a resposta está entre zero ou quase sempre para responder questão de prova. A questão é, seria o empecilho à falta de tato científico dos professores da educação básica e profissionalizante e/ou uma produção científica voltada para os próprios cientistas. De fato, as duas respostas nos parecem corretas, pois professores que nunca fizeram uma pesquisa científica certamente terão dificuldades em viabilizála a seus alunos, e a produção científica pautada de forma cética é a melhor forma de codificar o conhecimento a uma só classe, entre os mesmos que o produzem. Mas este conhecimento pode, sim, ser utilizado como instrumento de ensino. Demo (2003) retrata exatamente a importância da pesquisa científica ultrapassar a sofisticação acadêmica, o diletantismo e deixar de ser exclusividade dos cientistas, pois traz elementos do conhecimento especifico e geral, assim pode- 
se criar o enfoque globalizador e o pensamento complexo de Zabala (2002). Este pensamento complexo, para Morin (2001), é uma forma de reintegrar os conhecimentos dispersos numa visão global de realidade.

As pesquisas em Ensino de Ciências vêm crescendo nos últimos anos e um assunto muito abordado e discutido é a utilização de trabalhos experimentais como estratégia de ensino. Nessa perspectiva, um número significativo de especialistas em Ensino de Ciências propõe a substituição do verbalismo das aulas expositivas, e da grande maioria dos livros didáticos, por atividades experimentais (FRACALANZA et al., 1986). Apesar de muitas das vezes, em alguns determinados conteúdos, as aulas expositivas acabarem sendo uma das únicas alternativas que garantam êxito, o aluno se torna mais interessado quando se encontra fora do cotidiano, quando se sente desafiado e possibilitado a fazer descobertas por si só.

Segundo Macedo et al. (2013), "a formação de consciência científica é cada vez mais importante, uma vez que a ciência e a tecnologia têm tido intensa interferência na nossa sociedade atual". Assim, a experimentação tem que ter um papel diferenciado no ensino das ciências, estendendo também a qualquer ensino profissionalizante em que se trabalhe com estudantes na idade de formação de identidades. A experimentação tem que se preocupar não só em provar teorias ou motivar os alunos, mas também em ser vista como uma atividade provocadora de reflexão, uma estratégia capaz de suscitar discussões a partir das quais o conhecimento científico possa ganhar significado.

Para tentar retratar essa hipótese, foi feito uma atividade com os alunos do Centro Estadual Integrado a Educação Rural do município de Vila Pavão, no Espírito Santo, com o objetivo de comparar o conhecimento obtido dos alunos antes e depois de atuarem na elaboração, implementação, condução e discussão de uma pesquisa científica. Trazendo para a escola a discussão de métodos e metodologias de ensino onde o aluno seja um sujeito mais ativo no processo educacional. 


\section{PERCURSO METODOLÓGICO}

Como base para este estudo foi realizada uma pesquisa qualitativa em educação com procedimentos de estudo do método analítico descritivo (THOMAS \& NELSON, 1996), onde se aborda e se pratica observação de campo, experimentação, levantamento de questões de estudo e avaliação crítica dos fatos existentes. Tais processos se configuram na importância da pesquisa em todo âmbito educacional a fim de construir um campo de conceitos de base crítica, pois, segundo Demo (2003), o ato de relacionar o ensino e a pesquisa vai além de despertar a curiosidade no aluno, se apresenta como peça fundamental na construção do ator político capaz de criar soluções.

O trabalho foi desenvolvido no Centro Integrado de Educação Rural - CEIER de Vila Pavão-ES no ano letivo de 2012, com 13 alunos do $2^{\circ}$ período do curso Técnico em Agropecuária matriculados na disciplina de Extensão Rural. Em alguns momentos houve envolvimento de outras séries da escola, no intuito de ser aproveitar o máximo possível todos a atividades ocorridas no experimento para a construção de conhecimento.

O tema escolhido para o trabalho foi fixação biológica de nitrogênio (FBN), em virtude de sua relevância no cenário agrícola brasileiro e de ser um tema que visa à produtividade, sustentabilidade e manejo ecológico do solo. Para isso foi utilizado à cultura do feijão-caupi como dependente da FBN e sendo uma cultura base para a segurança alimentar, assim sendo empregada a técnica da inoculação de sementes utilizando diferentes estirpes (bactérias), oriundas da parceria com a Embrapa Agrobiologia.

Ainda na fase exploratória, foi proposta à coordenação pedagógica da escola a experimentação de novas metodologias de ensino/aprendizagem para aprimorar os conteúdos abordados no nível técnico de ensino do CEIER, já que havia muita preocupação por parte dos professores da área técnica em garantir aos alunos um ensino de qualidade que os preparasse para o mercado de trabalho, pois a escola carecia de estrutura em relação às novas tecnologias de mercado. Neste sentido foi exposto à coordenação pedagógica, de forma escrita e expositiva, as importâncias técnicas e pedagógica na utilização de um experimento de pesquisa como um instrumento metodológico tendo como suporte a orientação técnica de um doutorando curso de pósgraduação em Agronomia-Ciência do Solo (CPGA-CS) da UFRRJ. 
Após o entendimento com a coordenação pedagógica, deu-se inicio uma aula de FBN para os alunos do $2^{\circ}$ ano do ensino médio e técnico, abordando o tema de forma exploratória, e em seguida foi aplicado à turma um questionário com cinco questões referentes a um artigo intitulado “Eficiência agronômica de estirpes de rizóbios em feijão-caupi cultivado na região da Pré-Amazônia maranhense" de GUALTER et al. (2011), que abordava o tema da aula. O questionário abordava as seguintes questões: 1- O que você entendeu do resumo?; 2- Qual a sua principal dúvida no resumo? 3- Para você, qual a utilidade deste trabalho?; 4- Você já leu algo parecido com este texto? a) ( ) sim b) ( ) não; 5- Qual a nota você daria para este texto? a) ( ) 2 a 4, b) ( ) 5 a 7, c) ( ) 8 a 10.

Para o entendimento das respostas dos alunos foram adotados critérios nas correções em cada uma das questões, sendo: para a questão 1 foram adotadas quatro critérios na correção, os alunos que entenderam $0-30 \%, 30-60 \%, 61-90 \%$ e os que entenderam acima de $90 \%$ do trabalho; para a questão 2 foram identificadas cinco dúvidas presentes nas respostas dos alunos, sendo dúvidas referentes a tudo: Feijão-Caupi, FBN, Experimentação e a Bactérias; para a questão 3 foram identificadas quatro utilidades do trabalho presentes nas respostas dos alunos, sendo relacionada à fixação de $\mathrm{N}$ no Solo, à experimentação, a Bactérias e ao Feijão-Caupi; para a questão 4 foram adotados apenas os critérios de Sim e Não; e na questão 5 foram adotados os critérios de avaliação do trabalho lido por parte dos alunos. Estes dados foram transformados em porcentagem baseado no numero total de 13 alunos.

A segunda fase do trabalho foi a inserção de fato da pesquisa científica como método de ensino. Para isso, foi planejada com os alunos a instalação de um experimento em campo referente à FBN O planejamento passou pelas seguintes fases: 1- Escolha da área; 2- Analise de solo da área; 3Montagem de Croqui experimental; 4- Prática da inoculação de sementes e conhecimento de inoculante; 5- Instalação do Experimento; 6- Acompanhamento do experimento; 7- Coleta de nódulos do experimento; 8- Coleta da produção de grãos do experimento e 9- Discussão dos resultados. O experimento em si foi montado com o objetivo de avaliar a eficiência da FBN com a inoculação com seis tipos de bactérias (estirpes) diferentes, um tratamento sem inoculação e outro tratamento com adubação nitrogenada e sem inoculação. 
Figura 1. Acompanhamento do experimento em campo pelos alunos do $2^{\circ}$ período do curso Técnico em Agropecuária do CEIER-ES.

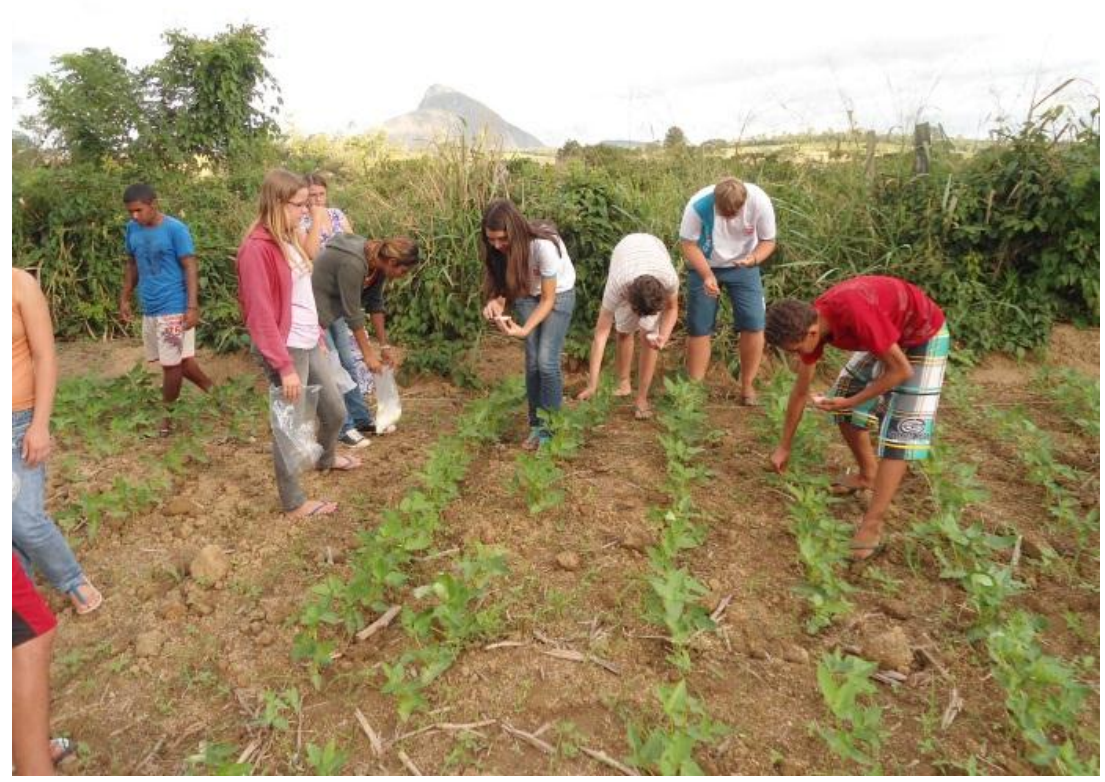

Fonte: dados da pesquisa.

A terceira fase foi a aplicação do questionário com as mesmas perguntas e com os mesmos critérios anteriores, porém com um novo trabalho e agora após a terem trabalhado diretamente com pesquisa científica. Foi escolhido o trabalho intitulado "Desempenho simbiótico de estirpes de bradyhizobium sp. no desenvolvimento e produtividade de grãos em feijão-caupi", de Nosoline et al. (2010).

Com relação aos tipos de estudos de caso empregados no ensino de Ciências, quatro se destacam na literatura: os estudos de caso científicos e sócio-científicos (Sá e Queiroz, 2009), os estudos de caso históricos (Stinner et al., 2003) e os estudos de caso de ensino (Merseth, 1996). Cada um deles é voltado para um contexto formativo específico.

\section{RESULTADOS E DISCUSSÃO}

Através dos questionários aplicados foi possível fazer um diagnóstico de conhecimento no campo dos conceitos científicos dos alunos do $2^{\circ}$ ano do ensino médio e técnico do CEIER, através das 
frequências de respostas dos questionários e dos conhecimentos adquiridos dentro do campo experimental a partir da contextualização dos conceitos através da proposta de estudo do método analítico descritivo.

Foi observado nos resultados da aplicação do primeiro questionário, na tabela 1, que a maioria da turma tinha dúvidas em todos os conteúdos no texto exploratório, mas mesmo com as dúvidas conseguiram compreender a importância do estudo científico e suas finalidades. Essa importância deve ser usada como primeiro passo da atividade provocadora de reflexão, pois na visão de ALVES et al. (2012) se o conhecimento científico é uma instância privilegiada de relações de poder, este conhecimento deve ser socializado, em vista que é considerado patrimônio da humanidade. MACEDO et al. (2013) retrata que os resultados de pesquisa científica podem chegar ao público geral em uma linguagem acessível por meio de artigos de divulgação, porém estes são em menor número e minimizam o conhecimento. Ainda sim é desacreditar na educação, pois a escola tem a capacidade de introduzir pesquisa científica no ensino e os alunos têm condições de se apropriar deste conhecimento com êxito, deste que usada às ferramentas coerentes, como demostramos neste trabalho.

Os resultados com o primeiro questionário (Tabela 1) permite observar uma dúvida frequente nas respostas com relação a "experimento", ao passo que é citado pela maioria como a utilidade do trabalho, isto mostra a necessidade da pesquisa científica na sala de aula como uma ferramenta potencializadora do ensino. Porém, é importante ressaltar que o uso do questionário, por mais que se identifique como avaliação, neste trabalho é entendido pela ideia de Álvarez (2002) como uma atividade de aprendizagem, sendo que o questionário aplicado após inserção da pesquisa científica assume como oportunidade do aluno poder por em prática os conhecimentos adquiridos. 
Tabela 1. Interpretação do texto aplicada antes do experimento.

\begin{tabular}{|c|c|c|c|c|c|}
\hline \multicolumn{2}{|l|}{ Questões } & \multicolumn{4}{|c|}{ Opções } \\
\hline 1- Compreensão do & $0-30 \%$ & $31-60 \%$ & $61-90 \%$ & $>90 \%$ & \\
\hline resumo? & 30,8 & 23,1 & 15,4 & 30,8 & \\
\hline \multirow{2}{*}{$\begin{array}{l}\text { 2- Principal dúvida no } \\
\text { resumo? }\end{array}$} & Tudo & Feijão-Caupi & FBN & Experimento & Bactérias \\
\hline & 23,1 & 23,1 & 15,4 & 23,1 & 15,4 \\
\hline \multirow{3}{*}{$\begin{array}{l}\text { 3- Utilidade deste } \\
\text { trabalho? }\end{array}$} & Fixar & Experimento & Bactérias & Feijão-Caupi & \\
\hline & $\begin{array}{l}\mathrm{N} \text { no } \\
\text { solo }\end{array}$ & & & & \\
\hline & 23,1 & 53,8 & 15,4 & 7,7 & \\
\hline 4- Você já leu algo & Sim & Não & & & \\
\hline $\begin{array}{l}\text { parecido com este } \\
\text { texto? }\end{array}$ & 23,1 & 76,9 & & & \\
\hline 5- Qual a nota você daria & 2 a 4 & 5 a 7 & 8 a 10 & & \\
\hline para este texto? & 0 & $92,3 \%$ & $7,7 \%$ & & \\
\hline
\end{tabular}

Fonte: dados da pesquisa.

Após a execução do experimento percebe-se através dos resultados tabulados do segundo questionário (Tabela 2), que o entendimento do texto exploratório em relação aos alunos que entendiam menos 31-60\% havia diminuído consequentemente as dúvidas em tudo diminuíram, porém a dúvida do conteúdo específico aumentou. Isso ocorre no momento porque foi proporcionado ao aluno na fase experimental (teoria/prática) uma gama de conhecimentos teóricos e práticos, quando os alunos reconheceram suas ações na sua visão de mundo dentro de sua realidade. Ao mesmo tempo que tal reconhecimento despertava sua curiosidade, ele também os atinava para questões variadas, relacionadas ao tema estudado e a outros temas do seu cotidiano. Assim, proporcionando aos mesmos um leque de informações, consequentemente proporcionou-se um leque de questionamentos, que neste sentido explicava a naturalidade das dúvidas no que diz respeito aos conteúdos mais aprofundados sobre assunto. Greenfield (2009) mostra que tecnologia na educação é uma ferramenta necessária, pois os meios digitais (televisão, vídeo games e internet) podem estimular a inteligência visual dos alunos que têm grande relevância em áreas científicas e tecnológicas, assim é providencial que a própria pesquisa 
científica possa ser usada como uma tecnologia na educação, refletindo em efeitos similares que os meios digitais, que em muitas escolas ainda são ferramentas distantes.

É importante ressaltar que, ao final do experimento, as dúvidas sobre o conteúdo de FBN eram zero, sendo esse o conteúdo mais esclarecido pelos alunos, segundo os dados da pesquisa. A pesquisa cientifica é uma ferramenta útil de ensino e pode sim ser caracterizada como uma tecnologia educacional. De acordo com Luppicini (2005), o termo "tecnologia" pode ser relacionado ao uso sistemático de qualquer tipo de conhecimento organizado. Mas, mesmo assim, quando diz respeito à utilidade deste trabalho experimental, as respostas ainda estão confusas, não relacionadas ao verdadeiro sentido.

Quando os alunos são questionados se já leram algo a respeito (Tabela 2), diferente da tabela 1 a maioria dos alunos afirmaram que já haviam lido algo parecido. Curiosa a resposta, mas coerente com o estudo, pois ao responderem a mesma pergunta pela primeira vez os alunos ainda não haviam tido familiaridade com o assunto. Depois do entendimento dos conceitos a partir da vivência de suas ações e da reflexão sobre elas, da capacidade de entendimento e discernimento do conteúdo do assunto abordado (Desenvolvimento e produtividade do Feijão Caupi a partir da inoculação se sementes), puderam entender que já tinham visto algo a respeito, mas de certo não tinham compreendido o assunto antes da utilização da pesquisa científica como instrumento de ensino. $E$, ainda assim, a introdução deste instrumento de ensino despertou a busca por conhecimento por parte dos alunos com relação ao assunto abordado. 
Tabela 2. Interpretação do texto aplicado depois de passado o experimento

\begin{tabular}{|c|c|c|c|c|c|}
\hline \multicolumn{2}{|l|}{ Questões } & \multicolumn{4}{|c|}{ Opções } \\
\hline 1- Compreensão do & $0-30 \%$ & $31-60 \%$ & $61-90 \%$ & $>90 \%$ & \\
\hline resumo? & 15,4 & 7,7 & 38,5 & 30,8 & \\
\hline 2- Principal dúvida no & Tudo & Feijão-Caupi & FBN & Experimento & Bactérias \\
\hline resumo? & 7,7 & 15,4 & 0,0 & 30,8 & 30,8 \\
\hline $\begin{array}{l}\text { 3- Utilidade deste } \\
\text { trabalho? }\end{array}$ & $\begin{array}{l}\text { Fixar } \mathrm{N} \\
\text { no solo }\end{array}$ & Experimento & Bactérias & Feijão-Caupi & \\
\hline & $46,2 \%$ & $7,7 \%$ & 7,7 & 15,4 & \\
\hline 4- Você já leu algo & Sim & Não & & & \\
\hline $\begin{array}{l}\text { parecido com este } \\
\text { texto? }\end{array}$ & $76,9 \%$ & $23,1 \%$ & & & \\
\hline 5- Qual a nota você & 2 a 4 & 5 a 7 & 8 a 10 & & \\
\hline daria para este texto? & 0 & $53,8 \%$ & $46,2 \%$ & & \\
\hline
\end{tabular}

Fonte: dados da pesquisa.

A crescente corrente para a utilização de novas tecnologias na educação (MACEDO, 2013; GREENFIELD, 2009; LUPPICINI, 2005; SAVIANI, 1994) mostra evidências de resultados significativos no processo de ensino aprendizagem. Porém, como exposto por Luppicini (2005), o termo tecnologia é bastante amplo, sendo frequentemente banalizado para representar apenas os meios digitais (GREENFIELD, 2009). Assim é importante ressaltar a ideia de Zabala (1998), que afirma que os materiais curriculares não podem substituir a atividade construtiva do professor e nem a dos alunos na aquisição das aprendizagens. Desta forma a pesquisa científica se faz um instrumento (tecnologia) que potencializa a atividade construtiva entre o professor e o aluno no processo de ensino aprendizagem.

Depois da execução do experimento os alunos se depararam mais críticos e mais curiosos ao se tratar de assuntos relacionados à FBN, Feijão Caupi, Bactérias e Experimento. Exposto que na leitura do segundo texto as observações dos alunos quanto sua relevância, abrangência dos assuntos entre outros contextos ficaram mais evidentes, já que a nota para o texto exposto aumentou consideravelmente. Nesse caso percebe-se que a iniciação experimental proporcionou 
aos alunos uma aproximação com os conceitos relacionados ao tema a partir das suas ações e reflexões sobre elas, no sentido de colocar o aluno como ator da sua própria realidade conduzido por um processo emancipatório (FREIRE, 1996; DEMO, 2003), neste sentido entendido como o aluno se ver participante da sua própria realidade a partir de suas próprias ações e ter a figura do professor como um facilitador.

Esse processo emancipatório não é uma atitude isolada, porque nada em sociedade é espontâneo estritamente. Precisa ser motivada, mas não pode ser conduzida. O filho não se emancipa sem os pais, mas estes precisam assumir uma postura instrumental de motivação. (DEMO, 2003).

É notório o avanço do conhecimento dos alunos após a realização do trabalho de pesquisa científica, que se constitui de uma ferramenta simples, barata e acessível ao ensino profissionalizante e também a outros. Mas conforme Demo (2009), os ambientes de aprendizagem devem ser pautados na qualidade e não dar mais importância a procedimentos e categorias, onde a autor deixa claro a necessidade da interatividade no compartilhamento progressivo da aprendizagem. Desta forma, assim como nos novos ambientes virtuais de aprendizagem, o professor na inserção da pesquisa cientifica não deve apresentar-se como dono prepotente e disciplinar do saber (DEMO, 2009). De forma sucinta pode-se classificar essa ferramenta didática como uma metodologia nomeada como aula científica globalizadora, baseado nas etapas descritas e na discussão inerente abordado pelo trabalho. 
Figura 2. Modelo simplificado explicativo do uso da pesquisa científica como ferramenta didática

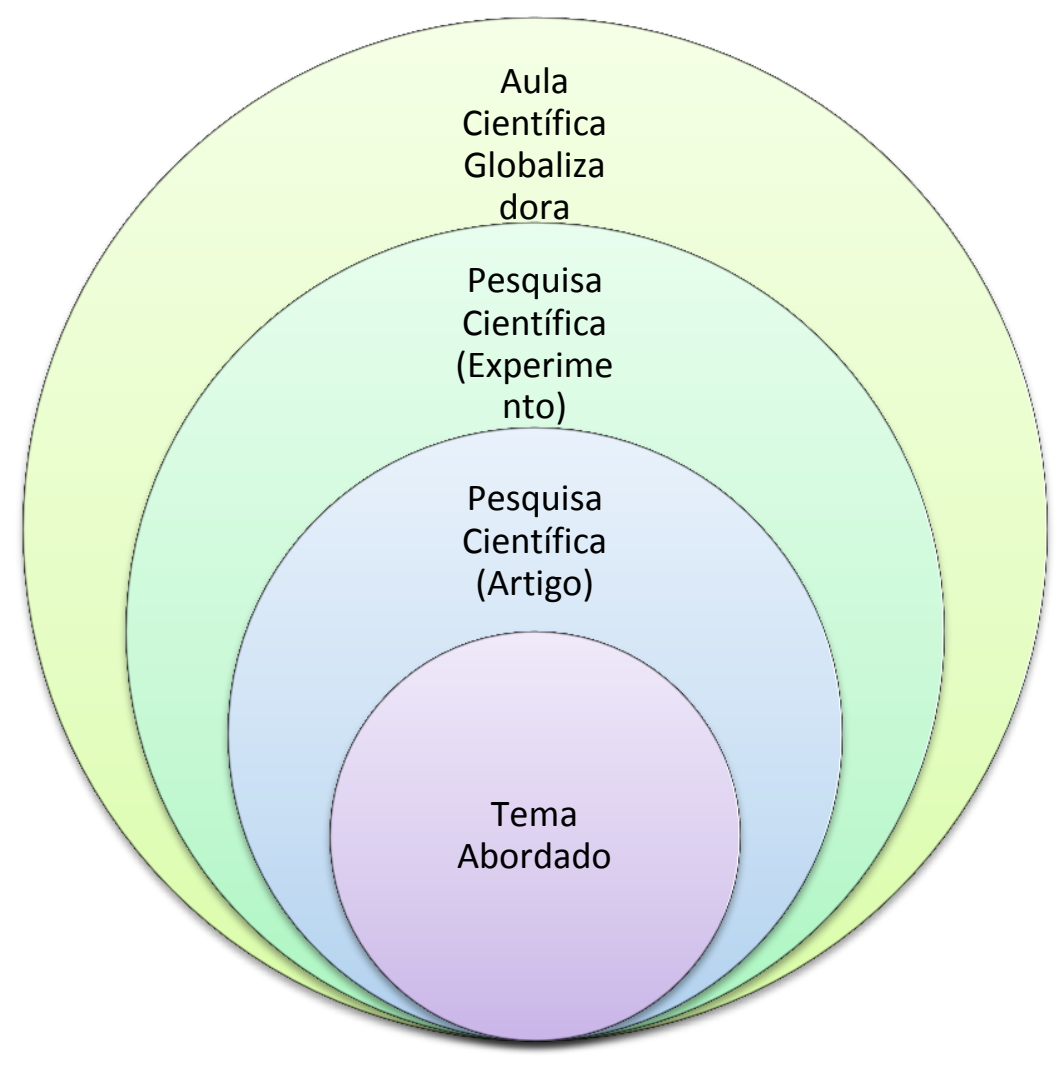

Fonte: dados da pesquisa.

\section{CONSIDERAÇÕES FINAIS}

O incentivo de aulas utilizando atividades experimentais é tão relevante quanto qualquer outra atividade escolar para a construção do conhecimento científico, sendo então importante no ensino Técnico Agropecuário. Os professores, alunos e coordenação pedagógica concordam com essas atividades, deixando claro que sua realização será sempre feita quando possível.

Para isso é necessário definir que tipo de experimentação cabe no ensino Agropecuário, e se atendem as necessidades dos campos conceituais exigidos na formação desse profissional para que ambas as parte possam de fato refletir, estudar, acompanhar, aplicar, questionar, contextualizar entre outras oportunidades de aprendizado que a pesquisa científica permitir no âmbito da construção de conceitos técnicos científicos, socioambientais entre outros. 
Fica exposto que a pesquisa científica contribui para ampliar horizontes conceituais, sendo esses relevantes na formação do aluno, e que não deixa de atender também a formação do Técnico em Agropecuária. Se os profissionais da educação conseguirem utilizá-la de forma que os alunos possam ser protagonistas de suas ações, já fica uma grande contribuição na formação de um profissional crítico em suas ações, sendo esse o objetivo principal de formação do Técnico em Agropecuária.

\section{AGRADECIMENTOS}

Ao Centro Integrado de Educação Rural-CEIER de Vila Pavão (ES) pelo apoio e iniciativa para construção do trabalho, em especial ao diretor Irineu Wutke e supervisora pedagógica Vilma Breger Scheraiber, assim como todos os professores que auxiliaram na condução do trabalho. E especificamente aos alunos, que foram fundamentais para o trabalho. Também ao curso de pósgraduação em Agronomia-Ciência do Solo (CPGA-CS) da UFRRJ e a Embrapa Agrobiologia.

\section{REFERÊNCIAS}

ÁlVAREZ, Juan M. Avaliar para conhecer, examinar para excluir. Porto Alegre: Artmed, 2002. (Coleção Inovação Pedagógica).

ALVES, L. P.; OLIVEIRA, E. A. M.; PAIVA, M. A. V. SEQUÊNCIA DIDÁTICA PARA VALIDAR UM MODELO CIENTÍFICO APROXIMANDO OS ESPAÇOS DE EDUCAÇÃO FORMAL DOS NÃO FORMAIS. Revista Eletrônica Debates em Educação Científica e Tecnológica, v. 2, n. 2, p. 81-93, 2012.

ANTUNES, R. (Org.). Os sentidos do trabalho. Ensaio sobre a afirmação e a negação do trabalho. 2a. Ed. São Paulo: Boitempo, 2000.

DEMO, Pedro. Educação hoje: "novas" tecnologias, pressões e oportunidades. São Paulo: Atlas, 2009. 137p.

DEMO, Pedro. Pesquisa: princípio científico e educativo, 10.ed. - São Paulo: Cortez, 2003, 120p.

FRACALANZA, H.; AMARAL, I.A.; GOUVEIA, M.S.F. O Ensino de Ciências no 10 grau. São Paulo: Atual. 1986. 124p.

FREIRE, Paulo, Pedagogia da autonomia: saberes necessários à prática educativa. São Paulo: Paz e Terra (Coleção leitura), 1996. 
GUALTER, R. M. R.; BODDEY, R. M.; RUMJANEK, N. G.; FREITAS, A. C. R. de; XAVIER, G. R. Eficiência agronômica de estirpes de rizóbio em feijão-caupi cultivado na região da Pré-Amazônia maranhense. Pesquisa Agropecuária Brasileira, v.46, p.303-308, 2011.

GRAMSCI, A. Cadernos do cárcere. Caderno 13: Maquiavel a política e o estado moderno. Rio de Janeiro: Civilização Brasileira, 2001.

GREENFIELD, P. M. Technology and Informal Education: What Is Taught, What Is Learned. Science, v. 323, p. 69-71, 2009.

LUPPICINI, R. A Systems Definition of Educational Technology in Society. Educational Technology \& Society, v. 8, n. 3, p. 103-109, 2005.

MACEDO, M. V.; NASCIMENTO, M. S.; BENTO, L. Educação em Ciência e as "Novas" Tecnologias. REVISTA PRÁXIS, v. 5, no 9, p. 17-23, 2013.

MACHADO, M. L. B. Formação Profissional e Modernização no Brasil (1930-1960): Uma Análise à Luz das Reflexões Teórico-Metodológicas de Lucie Tanguy. Educ. Soc., Campinas, v. 33, n. 118, p. 97-114, 2012.

MANFREDI, Sílvia Maria. Educação profissional no Brasil. São Paulo: Cortez, 2002.

MENDONÇA, S. R. A Dupla Dicotomia do Ensino Agrícola no Brasil. Estudos Sociedade e Agricultura, Rio de Janeiro, v. 14, $n^{\circ}$ 1, p. 88-113, 2006.

MOREIRA, I. C. A inclusão social e a popularização da ciência e tecnologia no Brasil. Inclusão Social, Brasília, v. 1, n², p. 11-16, abr./set, 2006.

MORIN, Edgar. A cabeça bem-feita: repensar a reforma, reformar o pensamento. Rio de Janeiro: Bertrand Brasil, 2001.

MURTA, Marinez. O Projeto Pedagógico da escola e o currículo como instrumento de sua concretização. Revista Educação e Tecnologia, v.9, n.1, p. 21-28, 2004.

NOSOLINE, S. M.; SILVA JÚNIOR, E. B.; PAULO, F. S.; OLIVEIRA, P. J.; RUMJANEK, N. G.; XAVIER, G. R. Desempenho simbiótico de estirpes de bradyhizobium sp. no desenvolvimento e produtividade de grãos em feijão-caupi. Anais do XXXIII Congresso Brasileiro de Ciência do Solo, 31 de julho a 05 agosto de 2011, Uberlândia-MG.

SANTOMÉ, Jurjo Torres. Globalização e interdisciplinaridade. O currículo integrado. Porto Alegre, Artes Médicas, 1998.

SAVIANI, D. $O$ trabalho como princípio educativo frente às novas tecnologias. In: FERRETTI,C. J. et al. (Orgs.). Novas tecnologias, trabalho e educação: um debate multidisciplinar. Petrópolis: Vozes, 1994.

TARDIF, Maurice. Saberes docentes e formação profissional. SP:Editora Vozes, 2002.

THOMAS, Jerry R. e NELSON, Jack K. Research methods in physical activity. Champaign : Human Kinetics, 1996, 3.ed.

ZABALA, Antoni. A Prática educativa: como Ensinar. Porto Alegre: Artmed, 1998.

ZABALA, Antoni. Enfoque globalizador e pensamento complexo: uma proposta para o currículo escolar. Porto alegre: ARTMED, 2002. 